(C) The Author(s), 2021. Published by Cambridge University Press on behalf of the Arizona Board of Regents on behalf of the University of Arizona. This is an Open Access article, distributed under the terms of the Creative Commons Attribution licence (http://creativecommons.org/licenses/by/4.0/), which permits unrestricted re-use, distribution, and reproduction in any medium, provided the original work is properly cited.

\title{
HEIDELBERG RADIOCARBON LAB - ESTABLISHING A NEW CARBON DIOXIDE EXTRACTION LINE FOR CARBONATE SAMPLES
}

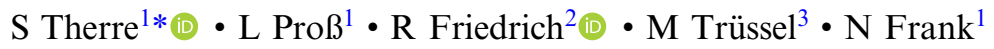 \\ ${ }^{1}$ Institute of Environmental Physics, Heidelberg University, Heidelberg, Germany \\ ${ }^{2}$ Curt-Engelhorn-Center Archaeometry, Mannheim, Germany \\ ${ }^{3}$ Stiftung Naturerbe Karst und Höhlen Obwalden (NeKO), Alpnach, Switzerland
}

\begin{abstract}
To achieve high-precision and reproducible results from radiocarbon $\left({ }^{14} \mathrm{C}\right)$ dating of carbonate samples in paleoclimate research, a new $\mathrm{CO}_{2}$ extraction line was designed, constructed, and characterized at the Heidelberg Radiocarbon Lab of the Institute of Environmental Physics, Heidelberg. The setup includes a circular glass-tube design, which is operated at vacuum pressure levels of the order of $10^{-5}$ mbar. The efficiency of the extraction process was assessed, showing significantly favorable conditions for solid piece samples $(99.58 \pm 4.69) \%$ over powdered samples $(88.28 \pm 10.03) \%$. Process blank values are below 0.2 pMC apparent ${ }^{14} \mathrm{C}$ activity. Repeated measurements of IAEA C2 standards with an average value of $(41.09 \pm 0.23)$ pMC attest high accuracy and reproducibility of the instrument. Six consecutive samples of 6 to $12 \mathrm{mg}$ carbonate mass can be processed in one run of roughly 2.5 hours. Thus, the new setup contributes to time-efficient and reproducible radiocarbon dating results for paleoclimate research at the Institute of Environmental Physics. In a first application, Dead Carbon Fraction (DCF) values of a Holocene alpine stalagmite from Schratten Cave are presented, revealing extraordinarily high offsets between atmospheric and stalagmite ${ }^{14} \mathrm{C}$ with DCF values between $(49.4 \pm 0.4) \%$ and $(61.6 \pm 0.4) \%$
\end{abstract}

KEYWORDS: $\mathrm{CO}_{2}$ extraction setup, paleoclimate research, radiocarbon sample preparation, secondary carbonates, stalagmites.

\section{INTRODUCTION}

At the Heidelberg Institute of Environmental Physics, radiocarbon $\left({ }^{14} \mathrm{C}\right)$ measurements of carbonate climate archives play a major role in paleoclimate research. In several studies, ${ }^{14} \mathrm{C}$ measurements were used to create age models of stalagmites (Fohlmeister et al. 2017; Warken et al. 2018). However, in combination with the established high-accuracy and highprecision U-series dating routine (Arps 2017; Wefing et al. 2017), ${ }^{14} \mathrm{C}$ can be used as a climate proxy to determine the influence of paleoclimate dynamics on ${ }^{14} \mathrm{C}$ reservoir ages of corals and stalagmites (Therre et al. 2020). To measure long-term trends as well as shorttime fluctuations of radiocarbon ages with high reproducibility, a reliable and robust ${ }^{14} \mathrm{C}$ sample preparation and measurement routine for carbonate samples is imperative. To this end, a highly efficient, circular carbonate extraction line was designed, constructed and characterized. The extraction setup is based on a glass tube structure operated under vacuum conditions, with a simple and practical operation procedure, while effectively avoiding contamination from ambient air $\mathrm{CO}_{2}$. Similar glass-based installations were previously reported on by Tisnérat-Laborde et al. (2001). Our setup provides the possibility to prepare six consecutive carbonate samples $(6-12 \mathrm{mg})$ in less than three hours at typical vacuum levels in the order of $10^{-5}$ mbar. After the extraction, samples are graphitized and subsequently measured by accelerator mass spectrometry (AMS), as was previously described in Therre et al. (2020). The established sample preparation procedure and the existing measurement facility provide the prerequisites for numerous future ${ }^{14} \mathrm{C}$ studies on paleoclimate archives.

\footnotetext{
*Corresponding author. Email: steffen.therre@iup.uni-heidelberg.de
} 


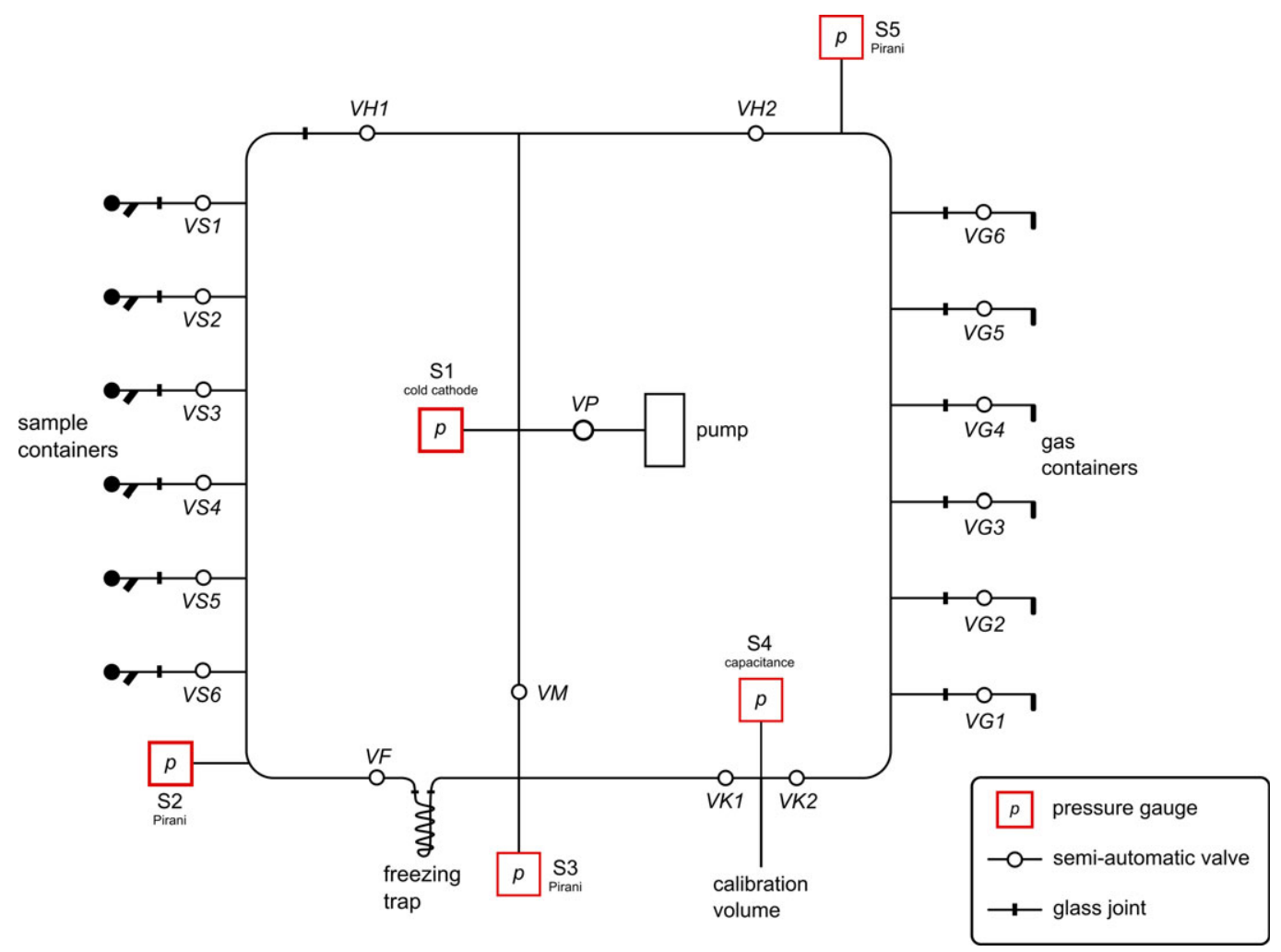

Figure 1 Schematic view of the new radiocarbon extraction setup. Carbonate samples are connected on the left branch. After hydrolysis, the water vapor is captured in the freezing trap and the $\mathrm{CO}_{2}$ is captured by liquid nitrogen and confined in the calibration volume, where it is reheated to lab conditions to determine the sample amount. After calibration, the sample is transferred to its respective gas container attached to the right branch. All six samples traverse the same distance due to the point-symmetric design of sample containers and gas containers. Pressure sensors in red, semi-automatic valves are depicted by white circles.

\section{CONFIGURATION}

\section{Setup}

The setup is schematically depicted in Figure 1. The instrument was designed in a circular configuration of borosilicate glass tubes which were custom manufactured in-house. A central evacuation pump (turbo-molecular/membrane pump stand of Type Pfeiffer Vacuum HiCube Eco) is located in the middle of the setup in order to provide reliable and evenly distributed levels of evacuation. Vacuum pressure levels of $10^{-5}$ to $10^{-6}$ mbar at the center of the extraction line (pressure sensor S1) can be achieved. Six carbonate samples can be connected to the evacuation line at once and can then be prepared consecutively. One freezing trap (dry ice/acetone mixture to produce temperatures of approximately $-80^{\circ} \mathrm{C}$ ) operates as a water trap for all samples.

A calibrated known volume is included in the setup to determine the absolute amount of extracted carbon dioxide to assess the efficiency of the extraction process allowing for the detection of incomplete sample hydrolysis. 
The valves (denoted with the prefix "V" in the figure) integrated in the setup are semiautomatic and allow for both pressure regulated and manual operation. Five pressure sensors (denoted with the prefix "S") are used to monitor the vacuum and extraction progress: One (S2) at the sample branch, (S3) at the freezing trap and (S5) at the gas-phase branch of the setup, respectively. A combined Pirani/capacitance gauge (S4) for accurate measurements of the $\mathrm{CO}_{2}$ pressure is connected to the calibration volume and one combined Pirani/cold cathode gauge (S1) at the center tube is used for surveillance of the ultimate pressure of the turbomolecular pump.

\section{Calibration Volume}

Incomplete hydrolysis of the carbonate samples may result in isotopic mass discrimination during the extraction process. To control the efficiency of the extraction reaction, a calibrated volume of known size confined by two valves (VK1, VK2) was added to the circular setup between the freezing trap and the gas containers. A capacitance pressure sensor was installed in this volume to provide accurate values of $\mathrm{CO}_{2}$ pressures.

In theory, the calculation of the substance amount, i.e., the mass of the resulting carbon dioxide, can be calculated by invoking the ideal gas law with the pressure $\mathrm{p}$, Volume V, mass $\mathrm{m}$, temperature $\mathrm{T}$ and molar mass $\mathrm{M}$ and the specific $\left(\mathrm{R}_{\mathrm{S}}\right)$ or universal gas constant $(\mathrm{R})$ :

$$
\begin{gathered}
p \cdot V=m \cdot R_{S} \cdot T \\
m=\frac{p \cdot V \cdot M}{R \cdot T}
\end{gathered}
$$

However, systematic errors of the capacitance gauge or of the volumetric measurement of the calibrated volume have to be taken into consideration. To that end, an additional calibration procedure was conducted by measuring the $\mathrm{CO}_{2}$ pressure in the calibrated volume for pieces of carbonate with precisely determined masses. The carbonate pieces were weighed on a high-precision analysis balance (precision: $0.01 \mathrm{mg}$, accuracy ensured by constant auto-calibration). The results of this experiment showed the expected linear relationship between carbonate mass and measured pressure in the calibrated volume in the relevant sample mass range $\left(\mathrm{R}^{2}=0.9977, \mathrm{~N}=9, \mathrm{p}<0.01\right)$. The calibration allows the calculation of processed carbon mass (in units of $\mathrm{mg}$ carbon, $\mathrm{mgC}$ ) from the $\mathrm{CO}_{2}$ pressure measured in the calibrated volume, assuming samples of pure $\mathrm{CaCO}_{3}$ and the molar mass ratio of calcium carbonate $\left(\mathrm{M}\left(\mathrm{CaCO}_{3}\right)=100.09 \mathrm{~g} / \mathrm{mole}\right)$ and carbon $(\mathrm{M}(\mathrm{C})=12.01 \mathrm{~g} / \mathrm{mole})$.

In addition to the absolute carbon mass extracted from the samples, the efficiency of the extraction reaction can also be assessed. Therefore, the actually measured pressure is compared to the expected pressure determined from the pressure-mass-calibration. The resulting ratio is interpreted as reaction efficiency $\eta$ :

$$
\eta=\frac{p_{\text {meas }}}{p_{\text {cal }}(m)}
$$

With $\eta$, the characteristics of different sampling methods can be determined, and the overall performance of the extraction setup can be characterized and monitored. 


\section{S Therre et al.}

\section{SAMPLE TREATMENT AND MEASUREMENT}

The setup is designed to extract $\mathrm{CO}_{2}$ from carbonate samples for AMS radiocarbon measurements, requiring approximately $1 \mathrm{mgC}$ of graphite (Synal et al. 2007; Kromer et al. 2013) after completed extraction and graphitization. An initial bulk mass of $6 \mathrm{mg}$ sample carbonate is sufficient for the subsequent AMS measurement, assuming the sample consists mostly of calcite. To avoid sample contamination before the extraction, pretreatment is required depending on the nature of the sample (powder, pieces, granulate etc.). Carbonate pieces are leached in hydrochloric acid $(4 \% \mathrm{HCl})$ for approximately one minute, then dried in a lab oven at $60^{\circ} \mathrm{C}$ for one hour. Since powdered samples cannot be leached in a comparable fashion, they are inserted in sample containers, evacuated and subsequently extracted shortly after sampling. Process blanks undergo the same treatment as other carbonate samples. They are sampled from carbonate materials (e.g., marble, IAEA C1 standard material or mid-Pleistocene stalagmites) older than the detection limit of radiocarbon of 50,000 years. Process blanks are prepared alongside samples to account for possible contamination during extraction or graphitization.

\section{Extraction}

Before the extraction procedure, the entire setup (see Figure 2a) is evacuated for approximately three hours to obtain stable, low pressure levels $\left(\mathrm{p}<10^{-5} \mathrm{mbar}\right)$. Afterwards, the samples are inserted into custom-made, cleaned borosilicate glass containers. As a hydrolyzing agent, $0.5 \mathrm{ml}$ of hydrochloric acid $(10 \% \mathrm{HCl})$ are injected into the acid compartments of the containers by a syringe. The loaded containers (see Figure $2 \mathrm{~b}$ ) are then connected to the extraction line via O-ring glass joints and subsequently evacuated through the freezing trap by opening valves VSX, VF and VM until pressures of $\mathrm{p}<10^{-4}$ mbar are obtained. After a leakage check the valves are closed and the hydrolysis reaction is started by turning the sample container until the acid can flow to the sample. Once the carbonate sample is completely hydrolyzed (seconds for powdered samples, ca. 1 minute for piece samples), the resulting gaseous mixture of $\mathrm{CO}_{2}$ and $\mathrm{H}_{2} \mathrm{O}$ is expanded into the dry ice/acetone freezing trap by opening VSX and VF where the emerging water vapor is removed at $-78^{\circ} \mathrm{C}$. After 2-3 minutes, valve VK1 is opened and the purified $\mathrm{CO}_{2}$ is collected in the calibration volume by a liquid nitrogen cooling trap at $-196^{\circ} \mathrm{C}$ for roughly $2-4$ minutes. Subsequently, VK1 is closed and the $\mathrm{CO}_{2}$ is heated to room temperature to obtain the pressure (S4) at lab conditions in the calibrated volume. Lastly, the $\mathrm{CO}_{2}$ is transported to gas containers (see Figure 2c) through liquid nitrogen cooling by opening valves VK2 and VGX, where the sample $\mathrm{CO}_{2}$ is confined. After each sample, the extraction line is evacuated for approximately 5-10 minutes to pressures of $\mathrm{p}<10^{-4}$ mbar, after which the next sample is extracted.

\section{Graphitization}

The $\mathrm{CO}_{2}$ containers are subsequently connected to a graphitization setup that is described and characterized in detail by Unkel (2006). To reduce $\mathrm{CO}_{2}$ to graphite, hydrogen gas is added to the reaction containers in a stoichiometrically determined ratio. As a catalyst for the reaction, 3 to $5 \mathrm{mg}$ of iron powder are put into the reactor tubes before loading the gaseous agents. The amount of iron is adapted based on the carbon mass from the extraction process to maintain an approximate ratio of $\mathrm{Fe}: \mathrm{C}=3$. The catalyst is chemically cleaned before the graphitization by oxidization with ambient air and subsequent two-fold reduction with hydrogen gas at $400^{\circ} \mathrm{C}$. Once the reactors are loaded, the reactors are heated to $575^{\circ} \mathrm{C}$ for $3-4$ hours until the pressure of residual gas in the reactors remains stable. During the reaction, the $\mathrm{CO}_{2}$ is converted first to 

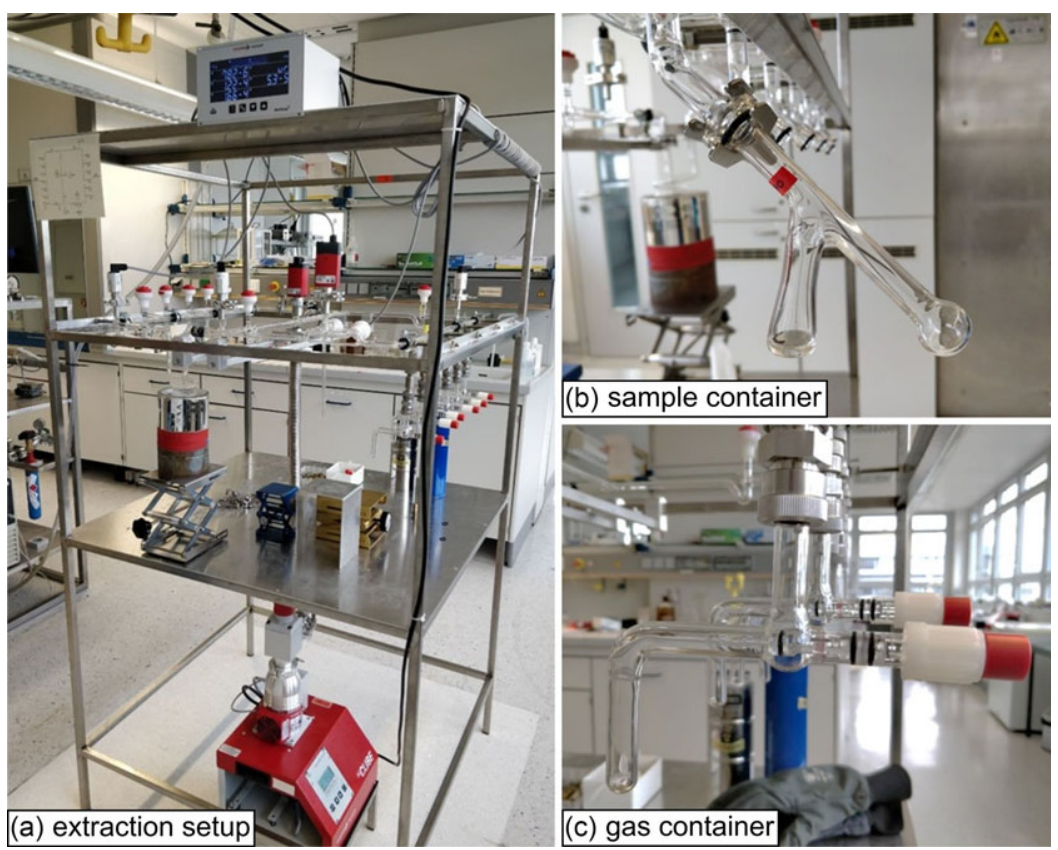

Figure 2 Extraction setup in operation at the Heidelberg Radiocarbon Lab with six samples (a). The carbonate samples are put into sample containers and connected to the setup with loaded acid reservoirs (b). The extracted $\mathrm{CO}_{2}$ is confined to gas containers at the end of the extraction (c).

$\mathrm{CO}$, subsequently to $\mathrm{C}$ and precipitates as graphite on the surface of the iron powder catalyst. After the reaction, the graphite/iron compound is stored in cleaned glass tubes until AMS measurement.

\section{AMS Measurement}

The AMS measurements for this study are carried out on the MICADAS AMS at CurtEngelhorn-Center Archaeometry (CEZA) in Mannheim, Germany. The measurement procedure is described in Synal et al. (2007) and the lab characteristics of CEZA were reported in Kromer et al. (2013). For the measurements the iron-graphite compound is pressed mechanically into metal targets and inserted into the $\mathrm{Cs}^{+}$ion source of the AMS. To calibrate the measured ${ }^{14} \mathrm{C} /{ }^{12} \mathrm{C}$ ratios and thus to obtain reliable radiocarbon dates, standards and blanks are measured in an alternating pattern together with actual samples during a measurement schedule. Oxalic-acid II standards (NIST 1983; Stuiver 1983) are used for calibration and the measured ratios are corrected for background and contamination obtained from blanks in the sample magazine.

\section{RESULTS AND ANALYSIS}

\section{Blank Results}

The limiting factor for radiocarbon measurements towards higher ages is the detection limit of the utilized measurement method. For MICADAS AMS, this limit is typically in the area of 49,000 to $51,000 \mathrm{yr}$, determined by the lowest ${ }^{14} \mathrm{C} /{ }^{12} \mathrm{C}$ ratio which can still be significantly 


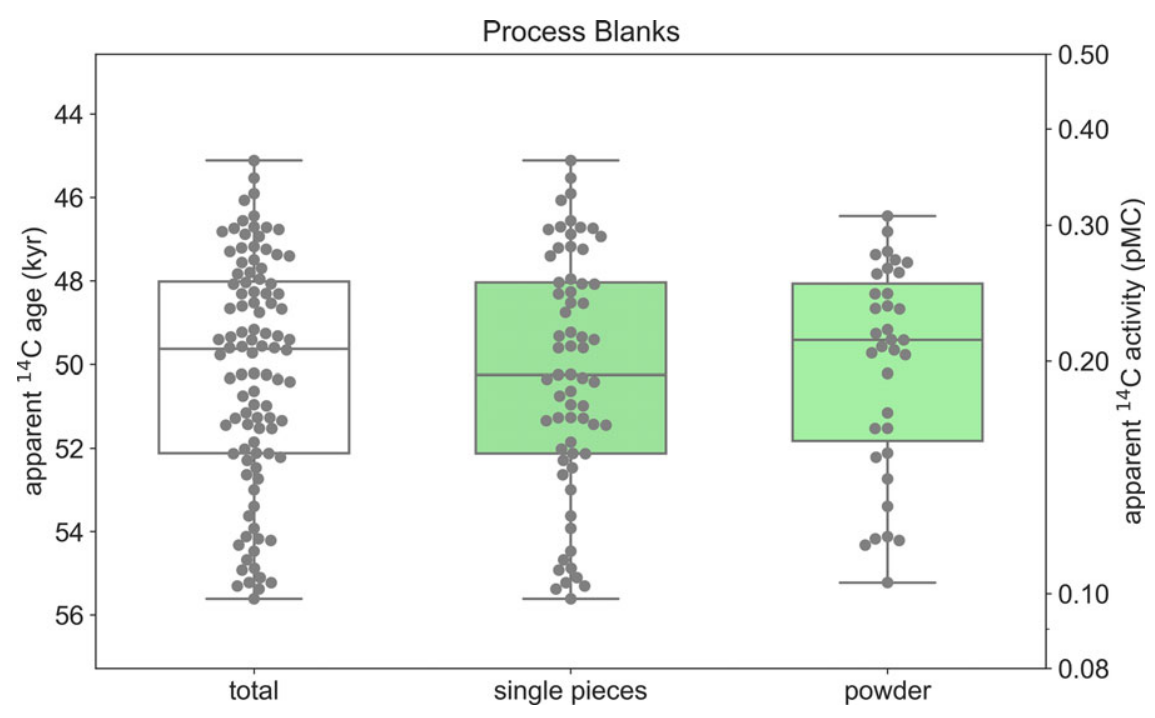

Figure 3 Blank results after preparation on the extraction setup, graphitization and subsequent AMS measurements in terms of ${ }^{14} \mathrm{C}$ years (left axis) and activity (right axis). The median apparent ${ }^{14} \mathrm{C}$ age of the overall distribution is 49,629 yr (median activity $0.207 \mathrm{pMC}$ ) with mean values of $(50,158 \pm 2711) \mathrm{yr}$ and $(0.205 \pm 0.065) \mathrm{pMC}$, respectively. Powdered samples have a mean activity of $(0.206 \pm 0.057)$ pMC and a median at 0.213 pMC. Solid, single piece samples show a slightly lower mean at $(0.204 \pm 0.069) \mathrm{pMC}$ and a median at $0.192 \mathrm{pMC}$.

distinguished from the machine background (Kromer et al. 2013). In addition, external contamination of the samples can limit the maximum age range where radiocarbon is still significantly detectable. The quantification of both machine background and sample contamination is achieved by processing and measuring blanks, as similar as possible to the sample, along with the other samples. Potential sources of contamination during the sample preparation include ambient air, (organic) residuals on the samples due to insufficient cleaning and memory effects from previous samples carried over during carbonate extraction or analysis.

Ongoing measurements of blank material from a marble block of geological age or a stalagmite with known U-series ages older than the detection limit of radiocarbon dating were conducted on the new setup since its installation. One hundred blank samples were prepared since the installation of the new extraction line, approximately a third of them as powdered samples which were taken with a hand drill, the other two thirds as cut solid pieces. The procedural blank samples ranged from 0.8 to $2.0 \mathrm{mgC}$ (mean: $1.27 \pm 0.27 \mathrm{mgC}$ ).

In terms of apparent ${ }^{14} \mathrm{C}$ activity, the total of measured blanks range between $0.099 \mathrm{pMC}$ and $0.364 \mathrm{pMC}$, with a mean of $(0.205 \pm 0.065) \mathrm{pMC}$ and a median activity of $0.207 \mathrm{pMC}$. All reported blanks are full system blanks without any other background correction applied, i.e., they represent the full background signal, including machine background. Considering the distinction between powdered samples and cut pieces of blank material, the 35 considered powdered samples scatter around their mean value $(0.206 \pm 0.057)$ pMC with a median of $0.213 \mathrm{pMC}$. While the mean of cut samples is quite similar at $(0.204 \pm 0.069)$ $\mathrm{pMC}$, the median of the distribution is lower at $0.192 \mathrm{pMC}$ (see Figure 3).

For the reported blank samples, no significant increase in blank pMC for lower carbon mass is observed. Other studies observed that this effect becomes relevant for blank carbon masses 
below $0.8 \mathrm{mg}$ in similar preparation and measurement configurations (Tisnérat-Laborde et al. 2001).

The median activities of cut samples and powdered samples are not significantly different. Nonetheless, it is in general recommended to choose the blank material and preparation technique as closely to that of the investigated samples as possible. Thus, results of blanks and samples become comparable and the eventual sample ages are more reproducible.

\section{IAEA-C2 Standard Reproducibility}

In addition to internal reproducibility of the preparation and measurement procedure, it is important to assess and maintain external reproducibility and accuracy by analyzing international standards. For that reason, the international IAEA C2 standard (travertine) (Rozanski and Stichler 1992) was prepared on the extraction line, graphitized and measured in the same way as all other samples. A total of 38 IAEA C2 standards was processed alongside blanks and samples over a period of two years resulting in a mean value of $(41.08 \pm 0.24) \mathrm{pMC}$ with a median of $41.12 \mathrm{pMC}$ (all reported values with procedural blank correction). Comparing this to the recommended value of $(41.14 \pm 0.03)$ pMC, this confirms the high accuracy and precision of the processing and measurement procedure with the new setup.

\section{Extraction Efficiency}

The extraction efficiency $\eta$ of the setup is mainly determined by the dissolution of the carbonate sample, and through loss of $\mathrm{CO}_{2}$ gas during the extraction due to leakage. The histograms of approximately 200 samples that were prepared using the new extraction line over 18 months of operation (119 piece samples, 79 powdered samples) show a significant discrepancy between powdered and solid single piece samples (see Figure 4). While single piece samples have a mean efficiency of $(99.58 \pm 4.69) \%$ and a median at $99.64 \%$. The histogram approximates a normal distribution around its mean value (Shapiro-Wilk-test: $p$ value $<0.001$ ), which is not significantly different from an efficiency of $100 \%$. The histogram of powdered samples is significantly more asymmetric with a strong tailing towards lower efficiencies. The mean efficiency of $(88.28 \pm 10.03) \%$ and a median at $91.47 \%$ confirm this observation. Efficiency values higher than $100 \%$ are the result of systematic errors during the weighing of the samples. The dissolution of powdered samples has a significantly lower efficiency than piece samples, due to their often incomplete reaction with hydrochloric acid. Once the hydrolysis agent is poured on the calcite powder in the evacuated sample container the reaction takes place almost instantaneously and the carbonate is catapulted upwards by the emerging gases. There, it partially adheres to the inner walls where the acid can no longer reach it and it remains in carbonate form. Therefore, solid pieces of carbonate are preferred for the extraction process over powdered samples.

\section{High Reservoir Ages in an alpine Stalagmite from Schratten Cave}

The lab routine was applied to determine the dead carbon fraction (DCF) of the Holocene stalagmite M6_1/20 from Schratten Cave, Switzerland (4647’ N, $8^{\circ} 16^{\prime} \mathrm{E}, 1782 \mathrm{~m}$ a.s.1.). The location of M6 in the Schratten Cave is overlain by an $85 \mathrm{~m}$ of limestone (Arps 2017). A combination of high-precision and high-accuracy U-series dating from Arps (2017) and Fohlmeister et al. (2018), performed on the MC-ICPMS instrument at the Institute of Environmental Physics, Heidelberg, and nine radiocarbon dating results obtained by the 
(a)

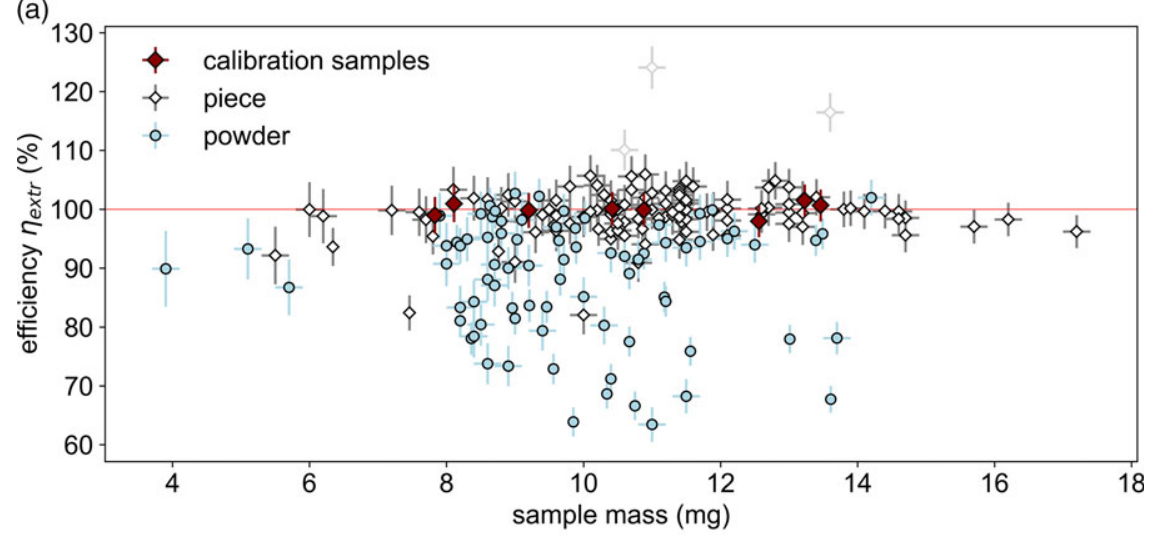

(b)

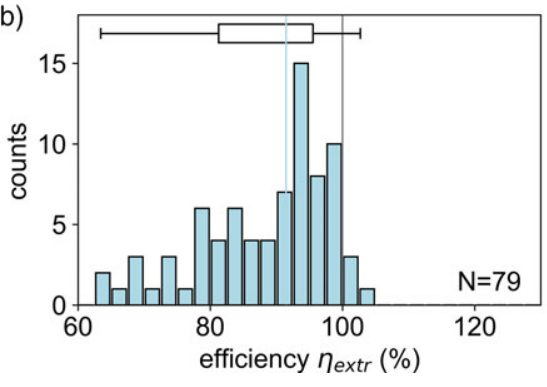

(c)

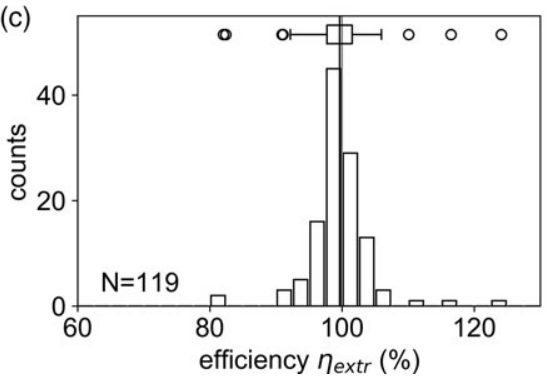

Figure 4 Efficiency assessment of almost 200 powder and solid single piece samples. In the top graph (a) the red line reflects $100 \%$ efficiency, as defined by the analysis of 8 calibration samples (red diamonds). Powdered samples generally produce lower extraction efficiency than solid single piece samples. A correlation of efficiency with sample mass is not observed. The comparison of sample configuration in histograms shows a distinct tailing towards lower $\eta$ for powdered samples, with a mean efficiency of $(88.28 \pm 10.03) \%$ (b), while single piece samples $\eta$ are normally distributed around a mean efficiency of $(99.58 \pm 4.69) \%$.

procedure described in previous sections was used. The data allowed the calculation and uncertainty modelling of the DCF according to the procedure described in Griffiths et al. (2012) and Therre et al. (2020) in reference to the recently published IntCal20 record (Reimer et al. 2020). The DCF time-series (Figure 5) revealed extremely high values above $50 \%$, with a high intra-record variability ranging from $(49.4 \pm 0.4) \%$ to $(61.6 \pm 0.4) \%$ over the last $6000 \mathrm{yr}$. Alpine speleothems have previously revealed extremely high levels of dead carbon that were attributed to the enhanced dissolution of limestone due to sulphuric acid or to aged organic matter contributions (Spötl et al. 2005; Welte et al. 2020), which augments the share of very old carbon in the dissolved inorganic carbon in the percolation water (Bajo et al. 2017). The DCF trend and variability in M6_1/20 opens the field for additional research to assess changing conditions of vegetation above the cave site and the input of sulphuric acid which adds to excess limestone dissolution in alpine regions. In the nearby Kaunertal, Austria, a distinct decline of the tree-line was reported after approximately 4500 yr BP (Nicolussi et al. 2005). Sinking tree lines imply a lower amount of active vegetation at the cave vicinity which would cause a reduced input of $\mathrm{CO}_{2}$ at nearatmospheric ${ }^{14} \mathrm{C}$ concentration into the soil zone. In this case, aging soil organic matter at a decreased ${ }^{14} \mathrm{C}$ signature might have contributed to soil $\mathrm{CO}_{2}$ at a higher proportion. A simultaneous significant shift of the growth rate is not observed (Arps 2017), which makes 


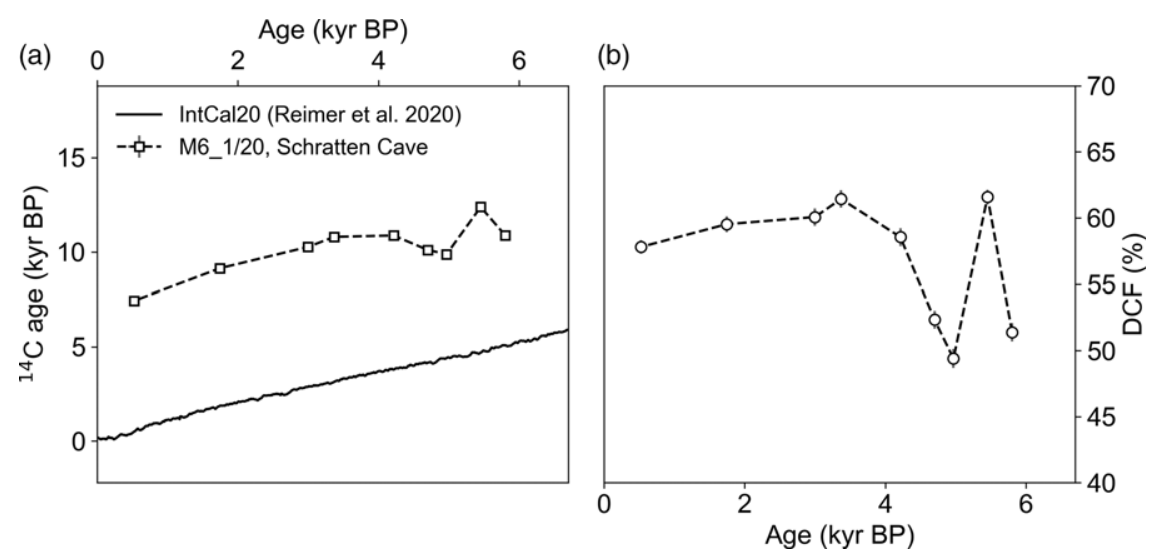

Figure 5 Radiocarbon ages of stalagmite M6_1/20 from mid to late Holocene. In comparison with the intercalibration record IntCal20 (Reimer et al. 2020), the offset of radiocarbon ages of stalagmite M6_1/20 is relatively high (a). This is reflected by extremely high DCF values up to $(61.6 \pm 0.59) \%$ (b).

a substantial change in the overall dissolution systematics and carbonate saturation of the percolation water unlikely. The relative decrease of ${ }^{14} \mathrm{C}$-rich input from the soil zone and persistent excess limestone dissolution in the karst caused a shift of the overall carbon composition of the percolation water towards older ages which resulted in a DCF increase. Our hypothesis offers a possible explanation of the even higher DCF values after $4500 \mathrm{yr}$ BP. This is a first hint towards a common climate signal in the alpine region approximately $4500 \mathrm{yr} \mathrm{BP}$, which requires further analysis with other climate proxies, in addition to ${ }^{14} \mathrm{C}$.

\section{CONCLUSION}

At the Institute of Environmental Physics, Heidelberg University, a new carbon dioxide extraction line for the radiocarbon sample preparation of carbonate environmental archives was successfully installed and taken into operation. Six consecutive samples can efficiently be extracted in rapid succession within three hours. Process blanks show an apparent ${ }^{14} \mathrm{C}$ activity of less than $0.2 \mathrm{pMC}$ on average and the international IAEA C2 standard was reproduced with great accuracy and high precision. The characterization of the extraction line and preparation procedure at the Radiocarbon Lab in Heidelberg sets the framework for high resolution ${ }^{14} \mathrm{C}$ studies of paleoclimate archives like stalagmites and corals. In combination with high-precision, high-accuracy U-series dating, ${ }^{14} \mathrm{C}$ can be used as an environmental proxy and tracer with special focus on past atmospheric ${ }^{14} \mathrm{C}$ variability and climate induced changes of ${ }^{14} \mathrm{C}$ signature.

\section{ACKNOWLEDGMENTS}

We would like to thank Rainer Stadler for his outstanding craftsmanship and his help constructing the glass setup, as well as Nadine Tisnérat-Laborde for her help in the planning of the setup. We would also like to thank Johanna Schwehn and Elvira Beisel for their help with the lab work. This project was funded by the DFG through the grant FR1341/4-1 and 4-2 and FR1341/12-1 to investigate the ${ }^{14} \mathrm{C}$ content of speleothems and cold-water corals. We thank Jens Fohlmeister for his vital contribution to these projects. 
The authors are very grateful to the editor-in-chief A. J. T. Jull, to associate editor Quan Hua, and to two anonymous referees for their constructive feedback and suggestions. Their comments considerably improved the quality of our article.

\section{REFERENCES}

Arps J. 2017. Towards €-precision of U-series age determinations of secondary carbonates. Heidelberg University.

Bajo P, Borsato A, Drysdale R, Hua Q, Frisia S, Zanchetta G, Hellstrom J, Woodhead J. 2017. Stalagmite carbon isotopes and dead carbon proportion (DCP) in a near-closed-system situation: An interplay between sulphuric and carbonic acid dissolution. Geochimica et Cosmochimica Acta 210:208-227. doi: 10.1016/ j.gca.2017.04.038.

Fohlmeister J, Arps J, Spötl C, Schröder-Ritzrau A, Plessen B, Günter C, Frank N, Trüssel M. 2018. Carbon and oxygen isotope fractionation in the water-calcite-aragonite system. Geochimica et Cosmochimica Acta 235:127139. doi: 10.1016/j.gca.2018.05.022.

Fohlmeister J, Plessen B, Dudashvili AS, Tjallingii R, Wolff C, Gafurov A, Cheng H. 2017. Winter precipitation changes during the Medieval Climate Anomaly and the Little Ice Age in arid Central Asia. Quaternary Science Reviews 178:24-36. doi: 10.1016/j.quascirev.2017.10.026.

Griffiths ML, Fohlmeister J, Drysdale RN, Hua Q, Johnson KR, Hellstrom JC, Gagan MK, Zhao J x. 2012. Hydrological control of the dead carbon fraction in a Holocene tropical speleothem. Quaternary Geochronology 14: 81-93. doi: 10.1016/j.quageo.2012.04.001.

Kromer B, Lindauer S, Synal HA, Wacker L. 2013. MAMS - A new AMS facility at the CurtEngelhorn-Centre for Achaeometry, Mannheim, Germany. Nuclear Instruments and Methods in Physics Research, Section B: Beam Interactions with Materials and Atoms 294:11-13. doi: 10. 1016/j.nimb.2012.01.015.

Nicolussi K, Kaufmann M, Patzelt G, Plicht van der J, Thurner A. 2005. Holocene tree-line variability in the Kauner Valley, Central Eastern Alps, indicated by dendrochronological analysis of living trees and subfossil logs. Vegetation History and Archaeobotany 14(3):221-234. doi: 10.1007/ s00334-005-0013-y.

NIST. 1983. Standard Reference Material 4990 C Oxalic acid - International Standard Reference Material for Contemporary Carbon-14.

Reimer PJ, Austin WEN, Bard E, Bayliss A, Blackwell PG, Bronk Ramsey C, Butzin M, Cheng $\mathrm{H}$, Edwards RL, Friedrich $\mathrm{M}$, et al. 2020. The IntCal20 Northern Hemisphere radiocarbon age calibration curve $(0-55$ cal kBP). Radiocarbon 62(4):725-757. doi: 10.1017/ RDC.2020.41.
Rozanski K, Stichler W. 1992. The IAEA ${ }^{14} \mathrm{C}$ intercomparison exercise 1990. Radiocarbon 34(3):506-519.

Spötl C, Fairchild IJ, Tooth AF. 2005. Cave air control on dripwater geochemistry, Obir Caves (Austria): implications for speleothem deposition in dynamically ventilated caves. Geochimica et Cosmochimica Acta 69(10):2451-2468. doi: 10. 1016/j.gca.2004.12.009.

Stuiver M. 1983. International agreements and the use of the new Oxalic Acid standard. Radiocarbon 25(2):793-795. doi: 10.1017/S0033822200006159.

Synal HA, Stocker M, Suter M. 2007. MICADAS: a new compact radiocarbon AMS system. Nuclear Instruments and Methods in Physics Research, Section B: Beam Interactions with Materials and Atoms 259(1):7-13. doi: 10.1016/j.nimb. 2007.01.138.

Therre S, Fohlmeister J, Fleitmann D, Matter A, Burns SJ, Arps J, Schröder-Ritzrau A, Friedrich R, Frank N. 2020. Climate-induced speleothem radiocarbon variability on Socotra Island from the Last Glacial Maximum to the Younger Dryas. Climate of the Past 16(1): 409-421. doi: 10.5194/cp-16-409-2020.

Tisnérat-Laborde N, Poupeau JJ, Tannau JF, Paterne M. 2001. Development of a semiautomated system for routine preparation of carbonate samples. Radiocarbon 43(2A): 299-304. doi: 10.1017/s0033822200038145.

Unkel I. 2006. AMS- ${ }^{14} \mathrm{C}$-Analysen zur Rekonstruktion der Landschafts- und Kulturgeschichte in der Region Palpa (S-Peru). Heidelberg University.

Warken SF, Fohlmeister J, Schröder-Ritzrau A, Constantin S, Spötl C, Gerdes A, Esper J, Frank N, Arps J, Terente M, et al. 2018. Reconstruction of late Holocene autumn/winter precipitation variability in SW Romania from a high-resolution speleothem trace element record. Earth and Planetary Science Letters 499:122133. doi: 10.1016/j.eps1.2018.07.027.

Wefing AM, Arps J, Blaser P, Wienberg C, Hebbeln D, Frank N. 2017. High precision U-series dating of scleractinian cold-water corals using an automated chromatographic $\mathrm{U}$ and $\mathrm{Th}$ extraction. Chemical Geology 475:140-148. doi: 10.1016/j.chemgeo.2017.10.036.

Welte C, Fohlmeister J, Wertnik M, Wacker L, Hattendorf B, Eglinton TI, Spötl C. 2020. Climatic variations during the Holocene inferred from radiocarbon and stable carbon isotopes in a high-alpine cave. Climate of the Past Discussions 2020:1-23. doi: 10.5194/cp-2020-110. 